\title{
POESÍA Y VIDA DE CORTE: LOS SONETOS EN EL CORTESANO DE LUIS MILÁN
}

\author{
Ines RaVASINI \\ Università degli Studi di Bari Aldo Moro
}

En el Libro de música de vihuela de mano intitulado El maestro, aparecido en 1536, Luis Milán recoge tres sonetos italianos «Amor, che nel penser mio vive et regna» de Petrarca, «Porta chiascun ne la frente signato» de autor anónimo y «O gelosia, d'amanti orribil freno» de Sannazaro'. Que el soneto encontrara acogida en la corte valenciana del Duque de Calabria, tan relacionada con ambientes italianos, es hecho que no sorprende; tampoco sorprende que, en un ambiente refinado como el que rodeaba al Duque y a Germana de Foix, su esposa, uno de los vehículos privilegiados de transmisión del género fuera la música. Menos obvia aparece en cambio la presencia consistente de sonetos en El Cortesano, obra de carácter misceláneo publicada en $1561^{2}$, que se presenta como una desmesurada pintura de la vida de la corte valenciana en la cual, a lo largo de seis jornadas y en el marco de un diálogo en el que participan varios personajes, se acumulan materiales poéticos y dramáticos de muy variada naturaleza y calidad. Texto complejo que, precisamente por la cantidad de materiales que acoge en sus páginas y por una estructura solo aparentemente desordenada, se resiste a una definición unívoca.

La obra, que pretende ofrecernos una representación en directo de la vida palaciega, podría leerse también como una antología de la lírica de la época ${ }^{3}$,

\footnotetext{
${ }^{1}$ Luis Milán, El Maestro, ed. de Charles Jacobs, University Park - London, The Pennsylvania State University Press, 1971, textos n. 37, p. 133; n. 38, p. 139; n. 70, p. 280.

${ }^{2}$ Libro intitulado El cortesano dirigido a la cathólica real magestad del invictíssimo don Phelipe [...] compuesto por don Luis Milán [...], Valencia, en casa de Ioan de Arcos, 1561. Para las citas se utiliza la edición facsimilar con transcripción moderna: Lluís del Milà, El Cortesano, ed. de Vicent Josep Escartí, estudis introductoris de Vicent Josep Escartí i Antoni Tordera, València, Biblioteca Valenciana Ajuntament de València - Universitat de València, 2001, 2 vols. En las citas, además de corregir algunos acentos e introducir mínimas variantes en la puntuación, aporto algunas correcciones o integraciones señaladas entre corchetes; las supresiones van marcadas entre $<>$.

${ }^{3}$ Un análisis profundizado de la variedad de géneros líricos en El Cortesano y de su sentido en el
} 
en la que predomina la poesía de tipo tradicional, con coplas, motes, glosas, redondillas y composiciones que remiten prevalentemente al ámbito de la poesía amorosa del siglo xv. En este contexto, la presencia del género italiano resulta especialmente significativa: como acaece en muchos de los cancioneros del siglo XVI, también en El Cortesano la poesía en metros italianos convive con la lírica tradicional y nuestro interés crece si consideramos que al lado de unos cuantos sonetos esparcidos a lo largo de la segunda y la tercera jornadas, en la última la presencia del género aumenta sensiblemente hasta incluir treinta y ocho, de los que veinticuatro constituyen un ciclo aislado que llega a configurarse como un pequeño cancionero dentro de la obra. Una breve antología que merece ser analizada más detenidamente tanto por el lugar relevante que ocupa en el conjunto del texto, como por sus características específicas.

El primer problema que plantean estos sonetos es el de su fecha de composición. Las características métricas y formales, muy lejos de la madurez y de la elegancia del modelo garcilasiano, delatan su carácter experimental y parecen apuntar a una época temprana, quizás a los mismos años en que Milán componía su libro de música acercándose a los sonetos italianos. De hecho, nos encontramos con un autor que no siempre domina el endecasílabo desde el punto de vista rítmico; por otro lado, de vez en cuando aparecen rimas agudas $^{4}$ y esquemas rímicos no siempre ortodoxos ${ }^{5}$ que invitan a colocar algunos

conjunto de la obra se puede leer ahora en Ignacio López Alemany, Ilusión áulica e imaginación caballeresca en «El Cortesano» de Luis Milán, Chapel Hill, Department of Romance Languages - The University of North Carolina, 2013 (en particular pp. 95-133). En los últimos años, tras la publicación de la edición de Escartí citada en la nota anterior, se ha asistido a un renovado interés de la crítica hacia $E l$ Cortesano: para una bibliografía detallada remito a la monografía de López Alemany recién publicada y que actualmente representa el estudio más amplio sobre esta obra de Milán.

${ }^{4}$ Véase, a título de ejemplo, estos versos en los que, además, aparece una alusión a Ausiàs March en el uso del senhal "Amor, amor", sobre el que volveré más adelante: «Dizen que sueños son gran vanidad / y a vezes vemos ser muy verdaderos, / mas veo mal en todos mis agüeros, / que hijos son de vuestra crueldad. / Amor, amor: ¿qué tengo de creer / pues tú me hazes reýr y llorar? / Hazme dormir, pues huelgo de ensoñar, / que vanidad a ratos da plazer [...]» («Gran bien durmiendo vengo a ensoñarme», vv. 5-12, p. 502). Para la presencia de rimas agudas en los sonetos, remito al clásico estudio de Francisco Rico, «El destierro del verso agudo. (Con una nota sobre rimas y razones en la poesía del Renacimiento)», en Homenaje a José Manuel Blecua, ofrecido por sus discípulos, colegas y amigos, Madrid, Gredos, 1983, pp. 525-552.

${ }^{5} \mathrm{Si}$ la mayoría de los sonetos reproducen los esquemas rímicos clásicos y más utilizados tanto en Italia como en España, es decir: ABBA ABBA CDE CDE (30 casos en El Cortesano) y ABBA ABBA CDC DCD ( 5 casos), no falta el esquema ABBA CDDC EFF EGG (8 casos) que no existe en Petrarca y tampoco aparece citado en las páginas dedicadas al soneto en los repertorios métricos italianos, aunque no sea posible descartar del todo la posibilidad de que exista algún experimento aislado, en la Italia de los siglos XIV y XV en el que esté documentada esta estructura anómala; esta forma, que parece un cruce entre el esquema rímico de la copla castellana de ocho versos con rimas abrazadas y el de la coda del sonetto caudato italiano, hace más bien pensar - por lo que atañe a los cuartetos- en la estrofa de Ausiàs March quien emplea este esquema en 90 de sus 128 poesías, véase Rudolf Baher, Manual de versificación española, Madrid, Gredos 1981, p. 285. También sobre este aspecto, volveré más adelante. 
de estos sonetos en una etapa experimental, de asimilación del género. Y si algunos de los versos cojean desde el punto de vista de los acentos, hay dos casos bastante singulares en el que el autor atribuye la definición de soneto a textos que, a pesar de su estructura canónica, se componen rigurosamente de versos dodecasílabos ${ }^{6}$. Como es normal en la fase de aclimatación del petrarquismo en España, también en este caso las formas italianas se conjugan con el lenguaje de la tradición lírica autóctona. Los sonetos de Milán, además, participan a menudo de esa actitud glosadora que, como estudió Giovanni Caravaggi ${ }^{7}$, caracteriza los primeros experimentos hispánicos alrededor del género. Este aspecto es aún más acentuado en El Cortesano, no solo porque a menudo los textos se construyen como una amplificación del íncipit o de los versos iniciales, a la manera de una glosa de mote, sino porque no pocas veces los mismos sonetos son, a su vez, objetos de paráfrasis en prosa. En este afán de explicar el texto, en el que se subraya además la relación que corre entre el desarrollo argumental y su distribución en cuartetos y tercetos, Milán nos permite entrar en el laboratorio del poeta y entender cómo va construyendo su texto.

Por otro lado, sin embargo, no hay que olvidar que si la crítica está de acuerdo en considerar El Cortesano como el reflejo, aunque a través del filtro de la ficción literaria, del ambiente de la corte valenciana alrededor de los años $1535-36^{8}$, tal unanimidad se atenúa a la hora de determinar la fecha de composición de la obra, considerando además que no se publicó hasta 1561 .

\footnotetext{
${ }^{6}$ Se trata de los 'sonetos' «Cabellos principian, cabellos fenescen» (p. 502) y «Señala las horas el norte su strella» (p. 513). También en este caso, aunque en la época temprana de asimilación de los metros italianos en España no falten ejemplos de confusión entre endecasílabos y versos de arte mayor (véase Baher, Manual, ob. cit., pp. 148-155), es bastante sorprendente encontrar esta forma a la altura del siglo XvI. Además, aunque Milán no domine perfectamente el endecasílabo, demuestra tener plena conciencia de los aspectos técnicos del verso italiano ya que, para los sonetos de la sexta jornada, a veces antepone al texto una indicación de carácter métrico para indicar la medida de los hemistiquios: 4+7 y $5+6$. En el caso de los dos sonetos en dodecasílabos, indica correctamente $6+6$ en el primer caso y en el otro, de manera menos clara, $5+6$. En los demás sonetos se encuentran versos mixtos $(4+7$ y $5+6)$. Además, en siete casos aparece la rúbrica «Soneto intercalado» sin que quede claro el significado de este término que no corresponde a una elección métrica particular, ni parece justificarse -por lo menos a un primer análisis- desde el punto de vista temático o de la estructura del ciclo de sonetos. Ya desde estos pocos elementos, es evidente que los aspectos métricos y la estructura del ciclo de sonetos de la sexta jornada merecen un estudio más detenido, también en la perspectiva de un análisis estilístico y sintáctico en la línea de los estudios de Dámaso Alonso, «Un aspecto del petrarquismo: la correlación poética», en Dámaso Alonso y Carlos Bousoño, Seis calas en la expresión literaria española, Madrid, Gredos, 1951, pp. 85-118 y de Elías L. Rivers, «Hacia la sintaxis del soneto», en Studia Philologica. Homenaje a Dámaso Alonso, Madrid, Gredos, 1963, vol. III, pp. 225-233.

${ }^{7}$ Giovanni Caravaggi, «Alle origini del petrarchismo in Spagna», en Miscellanea di Studi Ispanici, s.n. (1974), pp. 7-101.

${ }^{8}$ Josep Romeu i Figueras, «Literatura valenciana en El Cortesano», Revista Valenciana de Filología, 1 (1951), pp. 313-339 (pp. 324-325).
} 
Entre la tesis que supone una redacción cercana a los hechos retratados y la que propone una fecha próxima al año de su impresión ${ }^{9}$, cabe una tercera posibilidad ya que algunos elementos en el texto parecen justificar la hipótesis de una redacción dilatada, hecha quizás en épocas distintas, o por lo menos de una revisión por parte de Milán poco antes de que se publicara el texto ${ }^{10}$. No es esta la ocasión para entrar en una cuestión tan controvertida, aunque sí me parece oportuno llamar la atención sobre el hecho de que la intensificación de la presencia de los sonetos y su organización en un ciclo orgánico en la última jornada de El Cortesano, precisamente aquella donde se concentran los elementos que hacen pensar en un trabajo de revisión y puesta al día de la obra, podría representar otro argumento en apoyo de la tesis de una génesis compleja del texto y de una composición elaborada a lo largo de varios años, con la inserción en la redacción definitiva de materiales tanto nuevos como procedentes de épocas anteriores. La específica atención otorgada al soneto podría de hecho responder a los intereses de los lectores de la segunda mitad del siglo y constituir uno de los elementos introducidos en una segunda etapa o en una fase tardía de elaboración del texto. Pero, por el momento, se trata de una hipótesis en que habrá que profundizar estudiando mejor las relaciones entre estos sonetos y el resto de la obra.

La inserción de la mayoría de los sonetos en la sexta jornada de El Cortesano, treinta y ocho sobre un total de cuarenta y tres, todos de tema amoroso, parece además corresponder a una exigencia de coherencia temática ya que, por lo menos en su primera parte ${ }^{11}$, esta última jornada está enteramente

\footnotetext{
${ }^{9}$ Piensan en una fecha de composición cercana a 1535, Romeu i Figueras, «Literatura valenciana», art. cit., (aunque admite la posibilidad de que Milán aportara algunos retoques antes de la impresión) y Carla Perugini, «Biografía erótica de la corte valenciana (Luis de Milán y Juan Fernández de Heredia)», Analecta Malacitana, 32 (2012), pp. 297-320, el texto se puede leer también en formato electrónico en AnMal electrónica <http://www.anmal.uma.es/numero32/Corte_valenciana.htm> [última consulta: 10/05/2014]. Partidario de una escritura cercana a la fecha de publicación es, en cambio, Josep Solervicens, «El cortesano de Lluís del Milà i Il Cortegiano de Castiglione: notes per a una reinterpretació», en El diàleg renaixentista: Joan Lluís Vives, Cristòfor Despuig, Lluís del Milà, Antoni Agustí, [Barcelona], Publicacions de l'Abadia de Montserrat, 1997, pp. 169-191 (pp. 170-171, n. 172).

${ }^{10}$ La hipótesis de un proceso de escritura articulado en el tiempo es propuesta por Franco Meregalli, «La corte valenzana del Duca di Calabria ne El Cortesano di Luis Milán», Annali dell'Istituto Orientale di Napoli. Sezione Romanza, 30: 1 (1988), pp. 53-69 (pp. 62-63); en la misma línea, Antoni Tordera, «Drama i estratègies escèniques en El Cortesano», en Luis del Milà, El Cortesano, ed. cit., vol. I, pp. 99 172 (pp. 160-164); Ines Ravasini, «Crónica social y proyecto político en El Cortesano de Luis Milán», en Literatura, sociedad y política en el Siglo de Oro, ed. de Eugenia Fosalba Vela y Carlos Vaíllo, Barcelona, Universitat Autònoma de Barcelona - Servei de Publicacions, 2010, pp. 69-92; Ignacio López Alemany, Ilusión áulica, ob. cit., pp. 68-72.

${ }^{11}$ Como es sabido, El Cortesano se divide en seis jornadas: las primeras cinco corresponden a cinco distintos días, mientras que la sexta, rompiendo el paralelismo entre organización del texto y tiempo cronológico de la acción, abarca el espacio de tres días. Los treinta y ocho sonetos están todos en el primer día de la última jornada, junto con otros textos de tema amoroso.
} 
dedicada al análisis del sentimiento amoroso a través de materiales poéticos variados, de clara ascendencia "cancioneril", que van desde una tópica carta de amor, a las definiciones de las siete angustias y de los siete gozos de amor, incluyendo una canción amorosa glosada y unas jocosas coplas sobre la crueldad de una linda dama ${ }^{12}$. Materiales homogéneos que definen las características de la pasión de una manera sistemática y normativa, en particular en textos como las siete angustias y gozos de amor o en las sucesivas leyes de amor declaradas por los cortesanos al día siguiente. Tampoco hay que olvidar que el hipotexto en la base de El Cortesano de Milán es -como declara el mismo autor al principio de la obra ${ }^{13}$ - Il libro del Cortegiano di Baldesar Castiglione, y que esta intensificación en clave teórica del tema amoroso en el final de la obra parece inspirarse en la estructura del modelo italiano donde, en los capítulos finales, Bembo enuncia su visión neoplatónica del amor ${ }^{14}$.

Sin embargo, como apuntaba antes, los sonetos de la sexta jornada no son los únicos presentes en el texto: aunque de manera algo episódica, algunos aparecen ya en las jornadas precedentes, insertados en el tejido de la conversación palaciega, así que antes de focalizar nuestra atención sobre la selección principal de la sexta jornada, no será del todo inútil detenerse en estos sonetos aislados para mejor entender la presencia del género y su función dentro del contexto más amplio de El Cortesano. En el principio de la segunda jornada, Milán introduce el soneto «Con alta boz yo cantaré 1lorando» (pp. 258-259) en el que se describe la crueldad del dios de Amor y se identifica a la divinidad con la misma pasión amorosa: «¿Saben quién es el

\footnotetext{
${ }^{12}$ Se trata de una Carta de amor en coplas de nueve versos («Carta mía: pues que vas», pp. 472-477); otras coplas dedicadas a Las siete angustias de amor («Canten los gozos de amor», pp. 478-481); Los siete gozos de amor en coplas manriqueñas («Siete gozos cantar quiero», pp. 482-486); una canción («De piedra puedo dezir», p. 488) con su glosa («Sufro por vos tanto daño», pp. 488-492) y, finalmente, las coplas de Matalinda y Matacruel («Gran bien es pensar en vos», pp. 515-518) que declinan el tema del sufrimiento amoroso en tonos jocosos. Tampoco faltan composiciones sobre el amor en los festejos de los otros dos días que discurren a lo largo de la sexta jornada, como las diez leyes de amor en coplas castellanas dictadas por los cortesanos (pp. 536-549) o la representación de la Fiesta del Mayo (pp. 552-576).

${ }^{13}$ Dice Milán en la epístola proemial que abre El Cortesano: «Hallándome con ciertas damas de Valencia que tenían entre manos el Cortesano del conde Balthasar Castillón, dixieron qué me parescía d'él. Yo dixe: "Más querria ser vos, conde, / que no don Luys Milán, / por estar en essas manos / donde yo querría star". Respondieron las damas: "Pues hazed vos un otro para que halleguéys a veros en las manos que tanto os han dado de mano". Prové hazelle y á hallegado a tanto que no le han dado de mano, sino la mano para levantalle» (pp. 177-78).

${ }^{14}$ A pesar de la evidente distancia entre las dos obras con respecto al tono de la conversación, a los temas tratados y sobre todo al espesor teórico, repetidamente subrayada por la crítica, creo que la relación entre el texto de Milán y el modelo italiano es más sutil de lo que se ha venido delineando hasta ahora, como he intentado demostrar en otro lugar: ver Ines Ravasini, «Polifonia ed ecclettismo ne El Cortesano di Luis Milán», en Da Papa Borgia a «Borgia Papa». Letteratura, lingua e traduzione a Valencia, ed. Nancy de Benedetto e Ines Ravasini, Lecce, Pensa Multimedia, 2010, pp. 185-200; sobre la relación con Il Cortegiano, véase también López Alemany, Ilusión áulica, ob. cit., pp. 57-68.
} 
dios d'amor nombrado? / Tené por fe qu'es nuestro mal desseo / por dessear desvergonçadamente» (vv. 9-11). Según la costumbre, los otros personajes comentan el significado del texto a lo largo de una tertulia cuyo objetivo es «declarar al príncipe, debaxo jocosidad, el presente soneto» (p. 258). De hecho el texto es desmenuzado y analizado literalmente, empezando por los primeros dos versos, para seguir con los otros versos del primer cuarteto, desarrollar luego el segundo cuarteto y, finalmente, los dos tercetos, según una partición que respeta tanto los núcleos temáticos del texto como la estructura métrica del soneto. Esta explicación exhaustiva se mantiene fiel con el propósito de declarar «debaxo jocosidad» ya que, lejos de configurarse como un paréntesis teórico y didáctico, el comentario se insinúa en el diálogo brillante de los cortesanos, entremezclándose con burlas, juegos de palabras, anécdotas, cuentecillos que, de otra manera y en un nivel distinto, pretenden a su vez ilustrar el tema del soneto a través de la acumulación de diferentes materiales, estilos, modalidades de discurso. El efecto de esta interpretación coral y festiva es que si, por un lado, se amplifica el sentido del soneto trasladándolo a otros contextos y niveles de significación, por el otro, paradójicamente, su significado se reduce a anécdota cortesana, a caso personal, a charla divertida y maliciosa entre amigos. Ya desde esta primera aparición del género dentro de la obra, es evidente el esfuerzo de aclimatar el soneto dentro del discurso cortesano, conjugándolo con otros géneros tradicionales o peculiares de la tradición española y, a este propósito, resulta interesante el comentario de Diego Ladrón quien asimila el tono didáctico y algo críptico de los tercetos a la sentenciosidad enigmística de los motes: «Havéysme combidado a tercetos y hanme sabido a motes. Ni los unos ni los otros me han parescido mal, por ser vos el combidador» (p. 265) ${ }^{15}$. La conversación se cierra con un segundo soneto, introducido por un interesante preámbulo en el que el texto lírico se presenta como pausa en el largo intercambio de burlas y su autor exige el silencio de los demás, para no ser interrumpido con cuentos «fuera de tiempo»:

Dixo don Francisco Fenollet:

—Don Luys Milán: pues don Diego Ladrón os quebró la cabeça con su cuento y vos os havéys bien pagado con el vuestro, untalde los caxcos con otro soneto y quedaremos de las burlas en paz, con tan buenas veras como vos nos days. Respondió don Luis Milán:

\footnotetext{
${ }^{15}$ Que los cortesanos de Luis Milán tuviesen mucha familiaridad con el críptico conceptismo de los motes está demostrado por el papel relevante que este género juega dentro de la obra: véase Ignacio López Alemany, «"Lengua spada” y "buen palacio" en los motes eróticos y burlescos de El cortesano de Luis Milán», La corónica, 38: 1 (2009), pp. 315-331, ahora también en López Alemany, Ilusión áulica, ob. cit., pp. 95-117.
} 
- Soy contento, si no salle algún cuento fuera de tiempo, que los cuentos para nunca enojar han de ser en su lugar. Asseguralde y salirá.

Y respondieron:

-Él se assegura tanto como está seguro de no parescer mal.

Y con esta seguridad, el soneto salió diziendo ... (pp. 266-267) ${ }^{16}$

Una actitud esta que designa a Milán como el principal 'orquestador' de la obra, el que -junto al Duque- mantiene los hilos del discurso de los cortesanos, mide la oportunidad de sus intervenciones, establece cuándo es necesario callar o cambiar de tono. Una actitud que volverá a presentarse más adelante, precisamente con respecto al florilegio de sonetos de la sexta jornada.

Una análoga modalidad de presentación de los textos, citados y luego comentados gracias a paráfrasis literales por un lado y a conexiones con otros materiales textuales por el otro, se repite casi idéntica en la tercera jornada, donde encontramos dos sonetos («El gran Sansón se quexa de su amiga» y «Es tan común burlar de quien os ama», pp. 305 y 317) que tratan un aspecto más circunstanciado de la negatividad del amor o sea el motivo misógino de la crueldad femenina, ilustrado gracias al ejemplo bíblico de Sansón, traicionado por su amiga Dalila, y luego a la actitud de las mujeres en general, condenadas por burlarse de sus amantes.

En la sexta jornada, la introducción de los sonetos sigue, en cambio, dos distintas modalidades: la primera es la misma que Milán ha utilizado en las jornadas anteriores, con el soneto insertado en la conversación funcionando al mismo tiempo como breve pausa de descanso y como pre-texto para en seguida reanudar el diálogo, enriquecerlo con explicaciones, nuevas ideas y nuevos ejemplos tanto serios como burlescos, tanto en prosa como en verso. La segunda, en cambio, se caracteriza por la ausencia de conversación, ya que ahora los cortesanos callan y Milán entona sus sonetos, sin comentarios de los demás ni interrupciones de ningún género. Es esta la modalidad que caracteriza el ciclo de los veinticuatro sonetos, introducido por una explícita invitación al canto:

\footnotetext{
${ }^{16}$ Este segundo soneto, «De mí dirán aquel refrán muy cierto» (p. 267), insiste en el mismo tono didáctico al ilustrar los peligros del sentimiento amoroso: «Escarmentad $<\mathrm{a}>$, por bien en mal ageno, / y no burléys de quien muchos ha muerto. // No será pues mi prédica en desierto, / que mal amor peor es que veneno» (vv. 3-6). Los tercetos completan la advertencia llamando a la memoria «[...] aquel gran maestro, / del griego rey Alexandre nombrado / que fue d'amor de su muger vencido» (vv. 9-11), un exemplum clásico que en seguida Juan Fernández de Heredia se encargará de explicar para que mejor se entiendan las alusiones de los versos de su amigo. En la Jornada segunda hay además otro soneto, «Quiero passar por todos estamentos» (p. 278), en el que se sigue ilustrando la crueldad de Amor hacia sus seguidores, a través de la metáfora del combite al banquete de Venus y Cupido en el que «pocos yrán de su manjar contentos» (v. 5). Los tres sonetos de la segunda jornada presentan, por lo tanto, una evidente cohesión temática.
} 
El duque dixo:

- Yo sería de parescer que las damas de vuestra alteza oyessen la música de don Luys Milán, que mucho lo dessea. Mándelas venir, «que sin damas los galanes / no se muestran lo que son, / que piedratoque es la ocasión» ${ }^{17}$.

Las damas de la reyna vinieron, que la señora doña Leonor Guálvez, qu'es guión de la gala, habló á voluntad de todas, y dixo:

-Ya que en jubileo de música nos hallamos, pues por jubileo se dexa oýr don Luys Milán, las damas quieren mostrar «que de sabio es no mandar / e1 mandador, / que mandado es muy mejor», como veremos en vos, que hoy os dexaréys mandar de las damas, en dalles quanto os pedirán. Y la primera quiero ser yo, que os mando me cantéys sonetos vuestros porque gustemos de los sonsonetos, que nos harán bien callar y mejor hablar para entendellos. (pp. 493-494)

La invitación a Milán para que cante sus sonetos se configura, pues, como uno más de los entretenimientos cortesanos que animan la vida de la corte valenciana. Como en uno de esos juegos muy de moda en la época, de los que el mismo Milán nos ha dejado un precioso testimonio en su Libro de motes de damas y caballeros $(1535)^{18}$, las damas mandan al poeta que cante y lo hacen acudiendo a una de esas fórmulas poéticas que se utilizaban para invitar al juego, en el rebuscado estilo conceptista peculiar de este género de literatura lúdica. El discurso de Leonor Guálvez ilustra además otro elemento de reflexión sobre la práctica cortesana al introducir la noción de sonsoneto. En un artículo todavía inédito ${ }^{19}$, Ignacio López Alemany ha subrayado la importancia de este término que, a través de un juego de palabras generado por el cruce entre sonsonete y soneto, sintetiza de manera aguda esa peculiar forma de glosar las líricas al estilo italiano que hemos comentado anteriormente: el sonsoneto sería algo ligero que pretende ser el fruto de una improvisación y que alimenta el discurso de los cortesanos en sus veladas dedicadas a efímeros ejercicios

${ }^{17}$ Además de aportar mínimas correcciones al texto editado por Escartí (Lluís del Milà, El Cortesano, ed. cit.), utilizo las comillas para subrayar el carácter poético, muy al estilo de los juegos de mandar cortesanos, de algunos fragmentos del discurso del Duque y de las damas, siguiendo en esto la edición del Libro intitulado El cortesano compuesto por Luis Milán. Libro de motes de damas y caballeros por el mismo, Madrid, Aribau y C $C^{a}$. (Sucesores de Rivadeneyra), 1874, ahora también en formato electrónico: $<$ https://archive.org/details/colecciondelibro07almauoft $>$ [fecha consulta: 10/05/2014].

${ }^{18}$ Libro de motes de damas y caballeros intitulado el juego de mandar. Compuesto por don Luys Milán. Dirigido a las damas, Valencia, Francisco Díaz Romano, 1535; ed. facsímil, Valencia, ParísValencia, 1982; para una edición moderna, se puede consultar ahora El libro de motes de damas y caballeros de Luis Milán, ed. de Isabel Vega Vázquez, Santiago de Compostela, Universidade Servizo de Publicacións e Intercambio Científico, 2006, donde se analizan también las relaciones entre los motes de las dos obras de Milán (pp. 23-24).

${ }^{19}$ Ignacio López Alemany, «El sonsoneto cortesano y su discanto». Quiero agradecer al autor su amabilidad por haberme dejado leer este artículo aún inédito y por algunas observaciones sobre mi trabajo que me han resultado muy útiles. 
literarios ${ }^{20}$; un intento de aclimatar en la corte valenciana lo que en la Europa de la primera mitad del siglo XVI se consideraba la virtud principal del hombre de corte, es decir esa sprezzatura teorizada en el Cortigiano di Baldesar Castiglione (1528) y que aquí vemos aparecer en su declinación hispánica, a la vez irónica y lúdica. No insistiré más sobre estos rasgos a los que, como decía, López Alemany ha dedicado páginas interesantes que espero vean la luz pronto, limitándome a esta breve premisa, necesaria para poder colocar en la justa perspectiva también los otros sonetos de la sexta jornada.

En un determinado momento de la conversación, Milán pide para sus sonetos una forma de atención distinta; como había hecho ya en la segunda jornada, exige que el flujo de la conversación se interrumpa como condición para seguir cantando:

Dixo don Luys Milán al duque :

- Señor si más sallen cuentos, yo no sacaré sonetos.

Y todos dixeron que no dirían más.

La reyna dixo:

—Don Luys Milán tiene razón, que quando la música es de cavallero, hase de escuchar, si ya él no quiere hablar.

Y él dixo este soneto ... (p. 501) ${ }^{21}$

El sonsoneto deja lugar a la música: cuentos y cuentecillos desaparecen y la larga serie de veinticuatro sonetos ocupa ahora el espacio de la conversación, algo parecido a lo que hoy definiríamos un concierto para voz y vihuela, otra manera de disfrute cortesano del texto literario. En este sentido, esta sección del texto puede ser asimilada a la vertiente espectacular que también juega un papel de relieve en El Cortesano: de hecho, a lo largo de las seis jornadas Milán ha ido diseminando en sus páginas desfiles, desafíos, máscaras,

\footnotetext{
${ }^{20}$ Ya en la jornada tercera, Diego Ladrón había utilizado esta fórmula para introducir un soneto de Milán: «Dixo don Diego: "Señoras: si desseassen lo que don Luys Milán dessea, oyrían algún soneto suyo, que sus palabras son mejores que las obras de otro. Y desenojalde, que haze rostro de enojado, por ser alabado. Mánde[n]le que diga sonetos a damas, que por dezir sonsonetos, ésse deve ser su desseo". Dixo la señora doña Mencía: "Con licencia d'estas señoras, pues me lo mandan, diré. Si nuestros ruegos han de aprovechar, conformes serán nuestros desseos, para oýr tan buenas palabras como tienen sus obras". Don Luys Milán respondió: "Señora doña Mencía: con tan buen mandado, ¿quién no se dexará mandar? Y a donde con obras se ha de servir, no deve ser con palabras. Y no se me enojen del sonsoneto, pues la fin no's de enojar d'este soneto ..."» (pp. 316-317).

${ }^{21}$ No es raro el uso del verbo decir para introducir un soneto, sin que quede claro si el verbo alude a la recitación o al canto. En cambio, no hay duda de que algunos sonetos sean cantados y acompañados de música ya que así lo indican explícitamente los comentarios de los demás, como en esta ocasión en que hay una clara oposición entre la música y el hablar o más adelante cuando se insistirá en la diferencia entre cantar y contar un soneto, en el sentido también de comentarlo, ampliarlo (pp. 518 y 519).
} 
bailes y verdaderas representaciones como la Farsa de las galeras (en la tercera jornada), o la Fiesta del Mayo y la Máscara de Troyanos (ambas en la sexta jornada), todas manifestaciones de un fasto cortesano que alimentaba la práctica escénica de la época ${ }^{22}$.

La serie de sonetos cantados quedará interrumpida de repente por la Reina quien le pide a Milán que cante unas coplas dedicadas a una «burladora que servía» el autor, cuyo nombre era «una noche Matalinda y otra Matacruel», $\mathrm{y}$ «de palabra» cuente su historia (p. 515). Será el mismo poeta quien decida esclarecer el sentido de este nuevo texto, introduciéndolo con una anécdota personal sobre los múltiples «servidores» de la linda dama. La vuelta a la palabra determina que se reanude la práctica del sonsoneto, con su retahíla de cuentos, comentarios, burlas. Otra vez el cambio está marcado por comentarios metaliterarios que indican una clara separación entre estos dos modelos de fruición cortesana, una frontera entre el canto y la palabra, entre la escucha y la plática, entre poesía y glosa:

Dixo el duque:

—Don Luys Milán: si os cansáys de cantar, no's canséys de contar más sonetos que no son para cansar los graciosos sonsonetos. (p. 518)

Dixo don Luys Milán:

- [...] Y pues ya no he de cantar sino cont[ar] los sonetos, bien podremos discantar los sonsonetos.

Y comiençen a templar, que bien ay que discantar en mi soneto. (p. 519) $)^{23}$

Estos sonetos que pertenecen al ciclo cantado presentan una peculiar unidad de temas y motivos y parecen desarrollar una biografía sentimental que empieza con el amante en vilo entre sentimientos contrastantes, un tema anunciado desde el íncipit del primer texto de la serie («De bien y mal mi vida se sostiene», p. 501) y mejor explicitado en el primer terceto «Corro al morir y muerte no me quiere; / cansado stoy y siento gran descanso; / quiero llorar y voy de mí riendo» (vv. 9-11) y por la imagen final del león sumiso al amor: «Fiero león, amor le buelve manso, / que gran amor de sombras va

${ }^{22}$ La bibliografía sobre los episodios teatrales y festivos en El Cortesano es abundante: remito al estudio de López Alemany, Ilusión áulica, ob. cit., pp. 134-210 en particular, para un análisis detallado.

${ }^{23}$ No es indiferente que estos dos comentarios enmarquen el pasaje en el que Joan Fernández de Heredia explica, aunque de manera jocosa, las reglas para componer un soneto perfecto, casi como para reforzar el carácter normativo de estas declaraciones. «Contar sonetos» llega a ser prácticamente sinónimo de «sonsoneto», mientras que «discantar» alude a la misma divertida actitud glosadora: como en el caso de «sonsonete», aquí también un término musical contribuye a exaltar la función de controcanto, de concierto a más voces en que se traduce la conversación de los cortesanos. 
temiendo» (vv. 13-14). Esta oscilación entre bien y mal con que se abre la serie vertebra el ciclo entero y vuelve a aparecer ya en el segundo soneto («Gran bien durmiendo vengo a ensoñarme», pp. 501-502), dedicado al tema del sueño y de la incertidumbre entre verdad y mentira que el sueño conlleva. En la invocación al Amor para que le haga dormir («Hazme dormir, pues huelgo de ensoñar») se cela también el deseo de descubrir la verdad para poner término al vivir incierto: «O bien o mal, de ti sepa lo cierto, / que en fin es pena un bivir incierto» (vv. 13-14). El estado de incertidumbre se va intensificando hasta configurarse en el «Mortal dolor, con quien amor tormenta» (p. 503), un dolor que en el soneto siguiente asume las connotaciones del clásico estado de enajenación del amante:

Allá me voy, a do el amor me guía.

Soy como aquél que va en su pensamiento

qu'está muy fuera del conoscimiento, sino d'aquél que stá en su fantasía.

Pensando en vos, ¿quién ha d'estar en sí que por ydea en vos no se transforme?

Estoy sin vos y en vos tanto conforme que voy conmigo y nunca voy en mí.

Ni pie ni mano, la boca ni l'ojo no mandan ya, pues tal señora reyna.

Reyna's en mí tan absoluta reyna qu'en mí es plazer aquello que es enojo.

O bien o mal, avenga como quiera: vos sola soys mi voluntad postrera. (pp. 503-504)

La obsesión amorosa domina la fantasía y anula la facultad estimativa («Soy como aquél que va en su pensamiento / qu'está muy fuera del conoscimiento / sino d'aquél que stá en su fantasía», vv. 2-4), llevando al amante a identificar su voluntad con la mujer misma, y a aceptar el bien o mal que pueda generarse.

Delante de la imposibilidad de obtener el remedio por parte de la mujer, se intensifican el dolor y los presagios de muerte:

Pensando en vos, un no sé qué me enoja.

Sélo sentir y no dar a entender:

es un amargo en medio del plazer

$[\ldots]$

Soy como aquél que muestra ser mortal, 
que su acidente da señal de muerte:

si no mudáys de mal en bien mi suerte, dadme por muerto d'este grave mal.

Y es l'acidente ser desconfiado:

señal de muerte en qualquier estado. (p. 505)

El carácter unitario del corpus se percibe en el tono dominante de una negatividad acentuada: el amor es percibido como una fuerza negativa, un deseo insaciable, una enfermedad acrecentada por la visión de la mujer. De hecho, si quisiéramos buscar un desarrollo argumental, este consistiría precisamente en la progresión del sufrimiento y su manifestación física que se hace más evidente a medida que avanzamos en la lectura: «Sintiendo voy d'amor gran agonía; / la cara traigo de color de tierra» (vv. 1-2, p. 510), «Yo stoy mal sano, morirme querría» (v. 7, p. 511), «Yo sentí en veros el mal no temido, / por lo que dizen del mal de terciana» (vv. 1-2, p. 512) ...

Más adelante, Milán introduce un episodio pastoril: en el soneto «Al pie d'un monte, cerca d'una fuente» (pp. 505-506) el encuentro con un «pastor doliente» enfermo de amor, ofrece al amante la posibilidad de compartir el sufrimiento amoroso pero, al mismo tiempo, de reincidir en su voluntad de seguir amando:

Él yva en busca de sanadolores, qu'es una yerva que d'amor olvida. Yo la que nombran acuerda-amadores, que cualquier calça según su medida. (p. 506)

El elemento pastoril funciona como enlace con el soneto siguiente, «D'un árbol d'amor yo vi que colgava» (p. 506), breve alegoría sobre la pérdida de la esperanza: a la presencia de unas pastoras y unos pastores, el Amor invita al amante para que ciña su cabeza con una guirnalda de flores, símbolo del sentimiento amoroso, pero con solo tocarla, las flores se secan. La alegoría se transformará pronto en un presagio ya que la imagen de la flor seca volverá más de una vez para aludir a la pérdida de salud y a la muerte. El motivo aflora por ejemplo en el soneto «Nasció quando's vi, lo que no quisiera» (p. 509), conectado al tema de la visión de la amada: aquí es el amante quien se compara a una flor recién nacida y destinada a secarse en seguida:

Parezco la flor que muere nasciendo, que nasce en nascer la linda mañana del mayo gentil, que el mundo recrea, 
y dándole el sol se seca muriendo.

Tal soy y seré, por vuestra Dïana, que ver y cegar verá quien os vea. (p. 509)

En otro lugar («Como el dulçor de la dulce armonía», pp. 508-509), la imagen de la sequedad alude a la indiferencia de la mujer:

Despiértame teneros en memoria, qu'es un relox que me stá despertando, y en acordar, me hallo como a ñoria, que agua doy, mi gran ardor regando. Y siempre en vos hallo seca mi gloria, que sequedad, todo lo va secando. (p. 509)

En oposición a este mundo reducido a secano, en el soneto «Rosa d'abril cogida en la mañana» (p. 512) se introduce un insólito aire primaveral. La aparición de la mujer comparada con la «rosa d'abril» parece devolver la esperanza al amante al mismo tiempo que devuleve la vida a sus cinco sentidos. Sin embargo se trata de un efímero momento de felicidad, ya que esta misma visión de la amada será la causa, en el soneto siguiente («Yo sentí en veros el mal no temido», pp. 512-513), de otra enfermedad, la terciana de amor:

Yo sentí en veros el mal no temido, por lo que dicen del mal de terciana:

$$
\text { [...] }
$$

Malenconía de verme en olvido, en las entrañas de vuestra desgana causaron en mí la vida malsana que bivo por vos, y nunca e bivido. Terciana d'amor, es mucho más fuerte de frío mayor y más callentura; que, mis contrarios, de vos y mí vienen. D’estar fría vos, mi frío es de muerte, de yo no lo star, la vida me tura, que mal que es por bien estremos sostienen. (pp. 512-513)

Una condición que se resuelve en una última invocación al Amor, en el soneto que cierra el ciclo («Dulce cuydado y amargo desseo», p. 514):

$¡ \mathrm{O}$, dulce mal con hiel siempre a la boca!

Acaba ya de darme muerte o vida 
por ver quál es el fin de mi ventura.

Si soy de vida, ¿cómo es ya tan poca?

Si soy de muerte, acorta mi partida,

que mal d'amor sin fin no tiene cura. (p. 514)

Una concepción negativa del sentimiento amoroso domina en estos versos de Milán; el amor vivido como deseo y enfermedad, cierto sentimiento de resignación que empuja al amante a aceptar su destino en vilo entre el bien y el mal: «O bien o mal, avenga como quiera: / vos sola soys mi voluntad postrera» (p. 504) y también «A bien o mal, venga lo que viniere. / Sin este mal, menor mal me matara / que prosseguir con muy buena querella. / No muere, no, quien bive quando muere» (pp. 507-508).

En los últimos sonetos de la sexta jornada, ya fuera del ciclo de los veinticuatro cantados, se percibe un tono algo distinto: precisamente después del intermedio jocoso de las coplas de Matalinda y Matacruel, el tema de la crueldad femenina se hace central y el amante asume por momentos un papel agresivo y recriminatorio, a veces hasta insultante ${ }^{24}$ : la «dama real» del servicio de amor (p. 520) se transforma en «Doña Cruel» causa de un mal comparable al «mal francés» (p. 525), en «perra» que «mordió rabiando» (p, 527). Como si se hubiera superado una frontera estilística, marcada por las coplas que habían puesto fin al ciclo de los sonetos cantados, el lenguaje cortés se tiñe ahora de matices burlescos, conforme los sonetos van deslizándose otra vez hacia un contexto lúdico; entrelazados nuevamente en la conversación de los cortesanos, se exhiben ahora como la transcripción lírica de situaciones reales, casi como divisas que desenmascaran a los personajes, sus vicios y debilidades: a la luz de este entretenimiento de salón, el transgresivo e insultante apelativo de «perra mía» se resuelve así, en la acostumbrada glosa, en un inocente juego de palabras surgido del nombre de don Diego y de su apodo de Diego Perramor. Entre burlas y veras, aflora el tema de la locura de amor:

\footnotetext{
${ }^{24}$ «Dama real, vos days merescimientos / como da el rey, que todo le's devido, / mas crueldad y desagradescido / parescen mal en todos estamentos. // [...] Su crueldad me tiene muy deshecho; / por bien mirar me veo mal mirado» («No porfiar, hablando descontentos», vv. 5-8 y 13-14, pp. 519-520); «Nunca pensé que mal por bien viniesse, / y mal por bien por vos me ha venido. / Vínome el mal y todo m'á tollido, / que mal francés pensé luego que fuesse // Yo le rogué su nombre me dixesse, / y díxome: "Yo soy nombrado olvido. / Vengo a matar [a quien bien ha servido, / que el dios d'amor] mandó que yo lo hiziesse". // Doña Cruel, tu dama, fue la parte, / Ventura el juez; yo soy verdugo della. / Dize el pregón: "Est'es el desdichado" ...» (vv. 1-11, p. 525); «La perr'amor es esta perra mía, / que perra fue, pues me mordió rabiando, / no's enojéys si os voy acomparando / al animal, que más veros querria. // Es muy leal [a] aquél que d'él se fia; / es todo amor a quien lo stá halagando:/ no's ella ansí, m[a]s siempre va ladrando / para morder lo que sanar devria. // [...] No seáys vos lo que no soys ni fuistes, / que puesto que soys de hermosura dea, / lo que no's dios no sea matavida» (vv. 1-8 y 12-14, p. 527).
} 
¿Quién osaría, por mucho que osasse

tener tal ser de ser atrevido,

provarse con vos a braço partido

si no fuesse ya que desvarïasse?

Si mi loquear en esto parasse,

pues fuesse por vos, su seso perdido

merescería lo qu'es merescido.

¿Quién hizo al loco que le perdonasse?

A ley de razón, si stoy loqueando, pues vos lo causáys, yo soy desculpado, que no tiene ser quien es para poco.

Si loco con vos me viesse luchando, devría de ser de vos perdonado, que no's buen amor, si no's amor loco. (p. 528)

$\mathrm{Y}$ es precisamente ahora, al amparo de este lenguaje ambiguo suspendido entre cortesía y burla y bajo el velo de la locura de amor que empuja a desafiar a la dama, cuando vuelve a aflorar la urgencia del deseo que había caracterizado los primeros sonetos, ahora ya con una explícita referencia al amor carnal que suena como una verdadera infracción al código cortés, gesto atrevido y de desmesurada ambición que hace precipitar al amante en la desventura, definitivamente alejado de la divina hermosura femenina, como un nuevo Lucifer:

Espejo soys d'amor desamorado, para quien es a vos muy enojoso.

Mírase en vos, y no se vee hermoso, que feo stá un rostro desdeñado.

Y el que será muy hecho a vuestro grado, parescerá Narciso glorioso, que gentil es un feo venturoso, y no's gentil quien es desventurado.

Tal os miré, qual quedó por memoria un Lucifer, muy desfavorescido.

Vos un Luzbel, de muy gran hermosura.

Yo soy Luzmal, caýdo de la gloria, pues desseé ser yo con vos unido; que pena da lo que se desmesura. (p. 524)

El Cortesano revela ahora toda la complejidad de su articulada estructura puesto que, a lo largo de sus páginas, los textos líricos insertados son 
susceptibles de una doble lectura. De hecho la vinculación de los sonetos con su entorno dialógico avala una interpretación jocosa y relacionada con el efímero pasatiempo palaciego: los sonetos, anclados al hic et nunc del festejo cortesano, se vuelven motes, divisas de un estado de ánimo, rúbricas de una anécdota la mayoría de las veces cómica. Pero, si los aislamos de este contexto y los leemos como textos independientes (algo que el mismo Milán de alguna manera nos autoriza a hacer en el momento en que presenta la mayoría de los sonetos como algo desvinculado de la palabra cortesana), los podemos interpretar como un cancionero de amor en el que se perfila la historia sentimental de un amante rechazado que pasa del amor a la ira, del deseo a la locura, de la cortesía al amor hereos.

Es evidente, pues, a lo largo de las distintas jornadas y, aún más, en el ciclo de los sonetos cantados, la intención de crear un corpus coherente. En la antología de sonetos, aunque la unidad de estilo y de lenguaje remiten prevalentemente a la lírica amorosa del siglo xv, no faltan tímidas aperturas hacia un petrarquismo más ortodoxo, como en los versos «Yo retraté su gesto muy hermoso / y téngole perfeto retratado» (p. 521) que saben a reminiscencia garcilasiana o petrarquista ${ }^{25}$, o en el soneto dedicado a Hero y Leandro ${ }^{26}$, o incluso en el de ambientación pastoril comentado anteriormente. Pero a pesar de estas huellas, es evidente que el lenguaje, el uso de las figuras retóricas, la presencia bien arraigada del conceptismo cancioneril conectan estos sonetos a la tradición poética autóctona y en particular a la valenciana. En esta dirección me parecen significativas algunas huellas evidentes de Ausiàs March, como la reiterada invocación al $\mathrm{Amor}^{27}$ : «Amor, amor: pues mandas que yo pene, / sostiéneme, que muero desseando ...» (p. 501) y en otro soneto «Amor, amor: ¿qué tengo de creer / pues tú me hazes reýr y llorar?» (p. 502), acompañada de un uso abundante del símil tan frecuente en March: «Soy como aquél que va en su pensamiento...» (p. 503), «Soy como aquel que tienen al tormento...»

${ }^{25}$ López Alemany, Ilusión áulica, ob. cit., pp. 131-133 y n. 43, indica además del parecido con el soneto $\mathrm{v}$ de Garcilaso «Escrito 'stá en mi alma vuestro gesto», una posible reminiscencia del soneto LXXVIII de Petrarca por lo que concierne a la contemplación del retrato de la mujer, aquí vuelto en una clave jocosa: «[...] rato me days, que no sé qu'es reposo, / quando miráys, mirar desamorado; / tal me paráys, de vos muy mal parado, / que muérdome las manos de ravioso. // Y en veros tal, raviosa por matarme, / corriendo voy a ver vuestro retrato, / por descansar mirandos en pintura» (vv. 5-11, p. 521).

${ }^{26}$ López Alemany (ibídem, p. 126) señala en el v.7 de este soneto, «passando el mar d'amor tan verdadero», un posible eco del incipit garcilasiano: «Pasando el mar Leandro el animoso».

${ }^{27}$ La referencia es a Ausiàs March, LXXVII, v. 25: «Amor, Amor, un àbit m'é tallat», reproducido casi a la letra por Garcilaso en el soneto XxVII; el sintagma vuelve a aparecer en doce ocasiones en la obra de March: ver Costanzo Di Girolamo, «Introduzione», en Ausiàs March, Pagine del Canzoniere, ed. de Costanzo Di Girolamo, Milano-Trento, Luni Editrice, 1998, pp. 15-16. Para una visión de conjunto de los poemas marchianos que presentan el senhal "Amor, amor", véase Martí de Riquer, Història de la literatura catalana, Barcelona, Ariel, 1984, vol. III, pp. 182-197. 
(ibídem); un término de comparación este último, presente también en el poeta de Gandía ${ }^{28}$, así como la imagen de la flor mustia o del león, estas últimas quizás mediadas por Juan Fernández de Heredia ${ }^{29}$, el coprotagonista del Cortesano al lado de Milán. La misma insistencia sobre el motivo del deseo (el «muero desseando» del soneto «De bien y mal mi vida se sostiene», p. 501; la invocación «O, quién pudiesse bivir sin desseo, / por no saber qué cosa es dessear! [...] Son el desseo y el sospiro hermanos / y mi tristeza d'ellos es su madre: / vuestro desdén les es natural padre ....» ${ }^{30}$, p. 508; «Dulce cuydado y amargo desseo / me tienen puesto en prisión muy contenta», p. 514; etc.), su identificación con el amor ya desde el primer soneto de la segunda jornada, hacen pensar en la centralidad del desig en March. Los matices patológicos de la pasión con su componente físico, la mezcla de amargura y placer en la que se recrea el amante, los temblores de la fiebre de amor con sus accesos de frío y calor son todos motivos que, sin llegar a concretarse en préstamos precisos, muestran cierta afinidad con los versos de Ausiàs March. En esta perspectiva, como se apuntaba en el comienzo de este artículo, incluso la elección de un esquema rímico anómalo en la tradición petrarquista (ABBA CDDC EFF EGG), presente en ocho sonetos de Milán, podría representar - por lo menos por lo que atañe a los cuartetos- otro vínculo con el poeta catalán que privilegia la cobla con rimas ABBA CDDC, así como el predominio de endecasílabos con acento en la cuarta sílaba y cesura después de esta en nuestro poeta hace pensar en el decasílabo de la tradición lírica catalana.

Esta vinculación con el ambiente valenciano vuelve a aflorar en el excéntrico soneto de versos de doce sílabas dedicado al tema petrarquista de los cabellos más lucientes que el oro y el sol, que presenta analogías con un villancico del Comendador Escrivá, poeta valenciano ampliamente representado en el Cancionero General de Hernando del Castillo ${ }^{31}$ : en ambos textos encontramos no solo la imagen tópica de los cabellos que hieren como rayos, y la idea, esta menos frecuente, de la vida del amante colgando de los cabellos de la mujer,

\footnotetext{
${ }^{28}$ Ver Ausiàs March, LXXVIII, vv. 49-50: «Lo turmentat tem present passió / que met oblit al mal de ser defunt».

${ }^{29}$ Para la presencia de estos símiles en Juan Fernández de Heredia y su derivación de Ausiàs March, véase Maria D’Agostino, «Lengua, Lenguaje y Linaje nella poesia di Juan Fernández de Heredia», en Da Papa Borgia, ob. cit., pp. 171-184 (pp. 179-180).

${ }^{30}$ Quizás haya aquí una reminiscencia de las Lecciones de Job de Garci Sánchez de Badajoz: «Al desseo [dixe] "Padre / de mi crūel mal de amores, / de mis pensamientos vanos"; / a la muerte llamé "madre", / y a sus penas y dolores / dixe: "Vos soys mis ermanos"» (vv. 388-393); véase Patrick Gallagher, The life and works of Garci Sánchez de Badajoz, London, Tamesis Books, 1968, p. 152.

${ }^{31}$ No hay que olvidar, además, que una parecida actitud experimentadora a la hora de enfrentarse con los metros italianos aparece en otros poetas valencianos representados en el Cancionero General: piénsese por ejemplo en la «Sestina plañendo la muerte de la Reina doña Isabel» de Crespí de Valldaura y de Trillas.
} 
sino también el juego de palabras cabellos / cabe ellos para subrayar con una aguda paradoja la distancia que separa al amante de la amada:

Cabellos principian, cabellos fenescen mis altos cuydados de vida y de muerte.

De tales cabellos se cuelga mi suerte que matan al oro y al sol escurescen. Mi vista se altera mirándome en ellos: del todo turbado ni veo ni atino.

De mucho atinaros estoy tan sin tino que vengo a star lexos estando cab'ellos. Los rayos de Phebo, si ciegan no matan, mas vuestros cabellos me matan y ciegan: son rayos que passan, traspassan y allegan a ojos de un alma, que con ellos atan.

De cada cabello, me veo colgado, temiendo no quiebre de muy desdichado. (p. 502)

Y aquí el villancico de Escrivá que glosa un conocido estribillo «Los cabellos de mi amiga / d'oro son: / para mí lançadas son»:

Rayos son qu'ell alma encienden

de llamas que no se matan, lazos tienen con que atan los que más se les defienden; no tienen los qu'ellos prenden defensión:

para mí, lançadas son.

Y si los está peinando en lugar que pueda vellos, veo en cada uno d'ellos estar mi vida colgando; veo qu'están relumbrando el coraçón: para mí, lançadas son.

En mirallos conoscí ser mi muerte en su desvío, pues vi el nombre'n favor mío y sus obras contra mí: ¡cabellos, lexos me vi! 
¡Gran passión,

tal nombre y tal condición! ${ }^{32}$

La asociación del verso de arte mayor con un tema tan petrarquista come el de la comparación de los cabellos de la mujer con los rayos del sol, más cegadores que aquellos y más brillantes que el oro, metáfora de la hermosura femenina y de su poder desestabilizador, no deja de llamar la atención, considerado además que una análoga asociación reaparece en el otro soneto en versos dodecasílabos, «Señala las horas el norte su strella»; aquí la metáfora de la navegación amorosa, se vincula al tema de la visión de la amada y del rechazo por parte de ésta, en una escritura conceptuosa y no siempre clara:

Señala las horas el norte su strella, que norte del cielo d'amor soys, señora, mas nunca señala vengáys en buen'ora, quien horas amuestra de muerte, por vella. Es muy mal agüero, miralla y perdella: su cara me dize que vaya en mal'ora, la mala ventura muestra do mora; que vista señala lo qu'es de creella. Es como quien pierde, quien á de perderos, el mar que navega de vuestra belleza, qu'el norte, su strella, do pierde, la cobra, pues va navegando, por no meresceros, por Indias crueles de vuestra crueza, que todo bien falta do mucho mal sobra. (p. 513)

En ambos casos se trata de temas tópicos de la tradición petrarquista ${ }^{33} \mathrm{y}$ en ambos casos los sonetos en versos de arte mayor de Milán resuenan con ecos de la tradición de los cancioneros peninsulares. Baste recordar otro texto del Comendador Escrivá, la Nao de amor «De vida desamparado», en el que el amante privado de la visión de la mujer vive en un estado de muerte en vida:

De vida desamparado

pues no me quiere la muerte,

\footnotetext{
${ }^{32}$ Comendador Escrivá, Poesie, ed. de Ines Ravasini, Viareggio, Mauro Baroni, 2008, pp. 130-131.

${ }^{33}$ Para una reseña de textos petrarquistas en Italia y España alrededor de estos temas, véase M. ${ }^{a}$ Pilar Manero Sorolla, Imágenes petrarquistas en la lírica española del Renacimiento, Barcelona, PPU, 1990, pp. 200-233 (para la navegación), $495-510$ y 513-516 (para la metáfora del sol). Para un análisis de la metáfora de la tempestad de amor en la tradición lírica española, véase también Elisabetta Sarmati, Naufragi e tempeste d'amore. Storia di una metafora nella Spagna dei Secoli d'Oro, Roma, Carocci, 2009.
} 
¿qué haré?

Lleno de tanto cuidado, con tan desdichada suerte, dónde iré?

¿Qué haré, sin veros, yo?

¿Adónde podré llegar

que no sospire?

Pues, no viend'os, el que os vio

¿qué verá sino pesar

doquier que mire? (vv. 1-12) ${ }^{34}$

También en la Nao de Escrivá, el motivo de la estrella polar, guía para los navegantes, se transforma en imagen hiperbólica de la hermosura de la mujer:

\author{
El timón, la voluntad, \\ que a sólo veros me obliga \\ y a la muerte, \\ tras un norte de beldad \\ que mill vezes pierdo [a]1 día \\ por mi suerte (vv. 73-78) ${ }^{35}$
}

Como en el soneto de Milán, el riesgo que acecha al amante consiste en la pérdida de este norte de beldad, en el mar de la crueldad y del olvido femenino, algo muy distinto a la confianza que guiaba, por ejemplo, a Boscán en un soneto de tema análogo, «En alta mar rompido 'sta el navío»: «La 'strella, con la qual mi noche guío, / a bueltas de mi triste lassamiento, / alço los ojos por miralla atento / y dize, que si alargo, el puerto es mío» ${ }^{36}$.

Creo que para entender exactamente la presencia extravagante de estos dos sonetos en el conjunto de la serie, hay que colocarlos en el contexto cultural en que escribe Milán. En algunos artículos dedicados a Juan Fernández de Heredia, Maria D'Agostino ha estudiado la postura de este poeta, amigo de Milán, por lo que respecta a la versificación italiana, postura tanto más interesante si se considera que Fernández de Heredia estaba emparentado con Juan Boscán ${ }^{37}$. Unos textos inéditos ponen en evidencia la verve con que Heredia

\footnotetext{
${ }^{34}$ Comendador Escrivá, Poesie, ed. cit., p. 154.

${ }^{35}$ Ibidem, p. 157.

${ }^{36}$ Juan Boscán, Obra completa, ed. de Carlos Clavería, Madrid, Cátedra, 1999 (soneto c).

${ }^{37}$ Maria D’Agostino, «Apuntes para la edición crítica de la obra poética de Juan Fernández de Heredia», en Convivio. Estudios sobre la poesía de cancionero, ed. Vicenç Beltran y Juan Paredes, Granada, Universidad de Granada, 2006, pp. 319-335; ead., «"Que más acertara cualquier toscano / trocando su verso por el castellano": Juan Fernández de Heredia e la lirica italianeggiante», en Ogni onda si rinnova. Studi di ispanistica offerti a Giovanni Caravaggi, ed. Andrea Baldissera, Giuseppe Mazzocchi y Paolo
} 
entró en la polémica literaria acerca del estilo italiano que dividía entonces a los poetas castellanos, defendiendo la nobleza precisamente del verso de arte mayor frente a la octava rima y exaltando coplas y motes de amores:

El verso subido de arte mayor al músico oýdo mucho se enrima, quiçá los modernos dirán que es primor la gran gravedad del octava rima pues para damas será lo mejor.

$$
[\ldots]
$$

Llamado a expresar su opinión, Fernández de Heredia asume una actitud provocadora y disonante con respecto a las nuevas tendencias y concluye, «por ser de mi patria tan muy gran amigo», que «más acertara qualquier toscano / trocando su verso por el castellano», ya que en Castilla «se tratan con tal maravilla / coplas y motes d'amores ...». Una defensa apasionada de la propia tradición lírica que encuentra su confirmación en los pocos textos en endecasílabos escritos por Heredia y dados a conocer por Maria D'Agostino, en los que tras el verso italiano se percibe una concepción del amor en contraste con el código petrarquista y con las ideas de Bembo acerca del amor que se iban difundiendo en España, gracias también a la circulación y a la tradución del Cortegiano de Castiglione ${ }^{38}$.

«Coplas y motes d'amores» son materia que abunda en El Cortesano y, como se ha visto, también los sonetos de Milán pueden leerse como un intento de atraer las formas italianas en el cauce de la tradición amoroso-cortés autóctona. Creo que los dos sonetos compuestos en el verso de arte mayor pueden ayudarnos a dar un paso más en esta dirección: posicionados de manera especular dentro de la serie de los veinticuatro sonetos cantados (ocupan la tercera posición y la antepenúltima) podrían representar la respuesta a la invitación de Juan Fernández de Heredia a trocar el verso italiano por el castellano. Con una actitud entre provocatoria y lúdica, Milán recoge el desafío (casi como si se tratara de un enésimo juego de mandar) y utiliza el verso más noble de la tradición hispánica para realzar el soneto italiano, y para que el experimento

Pintacuda, Como - Pavia, Ibis, 2009, vol. I, pp. 289-307; «Lengua, Lenguaje y Linaje...», art. cit. En ocasión del Congreso «Si fe merescieren mis versos trobando». Forme, percorsi e destinatari della creazione poetica fra Quattro e Cinquecento (Roma, 15-16 maggio 2014) tuve ocasión de comentar algunos aspectos de estos artículos con la autora, cuyas sugerentes observaciones he tenido presentes a la hora de completar este trabajo.

${ }^{38}$ En esta misma línea me parece la lectura del soneto «Yo retraté su gesto muy hermoso» que propone López Alemany, Ilusión áulica, ob. cit., pp. 131-133. 
resulte en toda su evidencia, lo hace precisamente en dos textos marcadamente relacionados con la tradición petrarquista por lo que atañe a los temas.

En esta perspectiva, cobra mayor interés la relación de la serie de sonetos con los otros textos de El Cortesano: perfectamente alineados, como se ha dicho, con el tono general de las otras composiciones de la jornada sexta, en la que el tema del amor cobra especial relevancia a nivel teórico, de hecho los sonetos se entrelazan también con otros textos poéticos de versos octosílabos presentes a lo largo del entero diálogo, creando una serie de conexiones dentro de la obra. Solo por citar unos pocos ejemplos, el soneto «Yo retraté su gesto muy hermoso» se relaciona con el torneo de motes por el retrato de la dama de la segunda jornada, algunas de las imágenes primaverales de los sonetos reaparecen en la real caza de monte de damas y caballeros y en la Fiesta del mayo, el recuerdo de Durandarte en «Nunca pensé que mal por bien viniesse» (p. 525) trae a la memoria el romance «Durandarte, Durandarte» también en la segunda jornada. Es como si Milán hubiese querido reanudar una serie de temas aparecidos a lo largo de la obra y esta relación con otras secciones del texto, los enlaces intertextuales con composiciones en octosílabos, nos ayudan también a entender las razones profundas de la conexión entre formas italianas y estilo tradicional. Por otro lado, esta red intertextual es una prueba más de cómo, detrás de la acumulación aparentemente confusa de materiales heterogéneos, se esconde en realidad una arquitectura muy razonada y nada casual. En este sentido la serie de sonetos aislados no responde solo a una necesidad de variatio, o a la voluntad de poner en escena modalidades distintas de fruición del texto poético en el ambiente de la corte, y aún menos creo al deseo del autor de lucirse como exponente de la corriente italianizante. Muy al contrario me parece que Milán, de una manera no muy distinta de lo que hace Fernández de Heredia, utiliza el soneto para exaltar, jugando por contraste, el estilo de la lírica amorosa de tradición cancioneril. Sería interesante, ahora, leer estos sonetos teniendo a contraluz el texto del Cortegiano, para mejor medir la distancia entre las dos obras y calibrar la calidad de la relación que las vincula, más allá de las referencias explícitas y de las más obvias coincidencias superficiales. En la base de lo que hemos ido viendo hasta ahora, no excluiría que esta comparación nos reservara alguna sorpresa, algún atisbo de polémica hacia el neoplatonismo del modelo italiano.

Recibido: $16 / 06 / 2014$

Aceptado: 26/09/2014 


\section{(2)}

Poesía y Vida de Corte: los sonetos en EL Cortesano de Luis Milán

Resumen: El Cortesano de Luis Milán (1561) transmite, entre muchos otros materiales poéticos, una serie de sonetos muy interesantes tanto desde el punto de vista de su inserción en el conjunto de la obra como de la asimilación del petrarquismo en España. Si por un lado el análisis de esta pequeña antología permite delinear las distintas modalidades de fruición del soneto en el ámbito de la corte valenciana del Duque de Calabria, por el otro las relaciones con otros géneros líricos de la tradición hispánica, la estructura métrica, las conexiones intertextuales revelan una relación compleja con los modelos italianos y permiten profundizar en la recepción de la lírica italiana en la Valencia del siglo XVI y, más exactamente, en el círculo cultural que rodeaba al Duque de Calabria.

Palabras clave: El Cortesano. Luis Milán. Soneto. Petrarquismo. Lírica hispánica de los siglos XV-Xvi. Corte del Duque de Calabria.

\section{Poetry And Court Life: sonnets in EL Cortesano by Luis Milán}

ABstract: In El Cortesano (1561), Luis Milán includes, among other poetic material, a series of sonnets that are extremely interesting both on account of their relevance in the context of his work and because of how they reflect the influence of Petrarchism in Spain. An analysis of this short anthology shows how the sonnets were used in the court of the Duke of Calabria, while an examination of their relationships with other Castilian literary genres, of the prosody and of intratextual connections reveals the problematic relationship between these sonnets and the Italian tradition, and throws further light on the cultural reception of Italian poetry in the Duke of Calabria's court in Valencia during the $16^{\text {th }}$ century.

Keywords: El Cortesano. Luis Milán. Sonnet. Petrarchism. Spanish Poetry of $15^{\text {th }}$ and $16^{\text {th }}$ centuries. Duque de Calabria's Court. 